\title{
Analiza możliwości osadzenia powłoki $z$ azotku tytanu na powierzchni roboczej uszczelniającego pierścienia tłokowego silnika spalinowego
}

\author{
The feasibility of the titanium nitride coating \\ on the surface of the piston ring engine
}

\section{Streszczenie}

W artykule opisano możliwości wykonania powłoki z azotku tytanu na powierzchni roboczej pierścienia tłokowego silnika spalinowego. Powłoki te znajdują liczne zastosowania w przemyśle. W literaturze polskiej są one nazywane powłokami twardymi, natomiast w zagranicznej są znane jako powłoki ceramiczne. Powłokę z azotku tytanu zwiększającą odporność na zużycie ścierne można uzyskać na powierzchni roboczej pierścienia tłokowego, stosując różne technologie inżynierii powierzchni, np.: natryskiwanie plazmowe, technologie elektronowe, laserowe, implantacyjne, jarzeniowe, osadzania metodami CVD (Chemical Vapour Deposition) i PVD (Physical Vapour Deposition). Otrzymywane warstwy czy też powłoki, pomimo zastosowania tych samych składników, wykazują znacznie różniące się właściwości fizykomechaniczne. Celowe jest zatem rozpatrzenie możliwości osadzania powłoki azotku tytanu za pomocą wymienionych technologii, uwzględniając przy tym jej pożądane właściwości tribologiczne.

\section{Technologie elektronowe}

Technologie elektronowe umożliwiają obrabianie powierzchni nieobrabialnych w sposób konwencjonalny, zapewniając czystość obróbki z wyeliminowaniem odkształceń i zmian wymiarowych wsadu [11]. Ich wadami są: duży koszt nagrzewnic, konieczność zapewnienia wysokiej próżni i ochrony przed promieniowaniem rentgenowskim. Wady te są kompensowane dobrą jakością powłoki [13].

Do osadzenia powłoki azotku tytanu można wykorzystać natapianie elektronowe, gdzie w wiązkę

Dr hab. inż. Andrzej Kaźmierczak, prof. PWr - Politechnika Wrocławska.

\section{Abstract}

This paper describes the feasibility of the titanium nitride coating on the surface of the piston ring engine. These coatings are known for their range of applications in industry. In Polish literature they are called hard coatings, and in foreign literature meets to determine ceramic coatings. Titanium nitride coating increasing the wear resistance can be obtained from the piston ring face by applying the various technologies of surface engineering. Among these technologies can be distinguished: plasma spraying, electron, laser, implant, fluorescent, deposition methods, CVD (Chemical Vapour Deposition) and PVD methods (Physical Vapour Deposition). Obtained by the use of these technologies or the coating layer, despite using the same ingredients, significantly different physical and mechanical properties. Therefore it is advisable to consider the possibility of deposition of titanium nitride coatings using different, the above technologies, taking into account the desired tribological properties.

elektronów wprowadzany jest w postaci cząstek materiał powłokowy [30]. Największe potencjalne zastosowanie wiązki elektronowej do tworzenia powłoki azotku tytanu jest spodziewane po technologiach odparowaniowych, w których wiązka elektronów doprowadza materiał powłokowy (np.: tytan) do fazy lotnej w postaci par i ich osadzenia metodą PVD po przereagowaniu z gazem reaktywnym (tu: azotem) na podłożu. Za pomocą tej metody można uzyskać dobrze przylegający azotek tytanu [14]. Inną technologią jest wykorzystanie wiązki elektronów do obróbki uprzednio naniesionych innymi metodami powłok [30]. Uzyskuje się wówczas zwiększenie twardości i odporności na ścieranie, wysoką temperaturę, erozję i utlenianie,

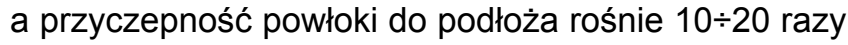
dzięki procesom dyfuzyjnym w strefie połączenia. 
Technologia ta wymaga prowadzenia obróbek powierzchniowych, co pomimo dowolnie grubej powłoki azotku tytanu (nawet do $100 \mu \mathrm{m}$ ) czyni ją nieopłacalną.

Reasumując, największe potencjalne zastosowanie wiązki elektronów to użycie jej do odparowania tytanu i następnie osadzenia jego azotku (powstałego po reakcji chemicznej z gazem reaktywnym) metodami PVD na pierścieniu.

\section{Technologie laserowe}

Technologie laserowe można stosować samodzielnie lub jako proces dodatkowy w innych metodach, np. CVD lub PVD. Do wytwarzania powłok z azotku tytanu można zastosować: wtopieniowe stopowanie gazowe, odparowanie czyste, pirolityczne wytwarzanie powłok lub chemiczne wytwarzanie powłok $[19,36]$.

Wtopieniowe stopowanie gazowe jest procesem umożliwiającym otrzymywanie powłoki z azotku tytanu lub jego stopów uprzednio natryśniętych na dowolne podłoże metalowe. Grubość otrzymanej powłoki azotku tytanu wynosi ok. $100 \mu \mathrm{m}$, czyli ponad 10-krotnie więcej niż w metodach PVD i CVD. Otrzymana powłoka wskutek intensywnych ruchów konwekcyjnych nie wykazuje budowy warstwowej. Wszystkie fazy w strefie przetopionej są równomiernie rozłożone na całej jej głębokości. Wyjątek stanowi faza dyfuzyjna na granicy faz stałej i ciekłej, dzięki której połączenie warstwy z podłożem ma charakter metalurgiczny. Powstała powłoka wymaga obróbki wykańczającej.

Odparowanie czyste jest procesem wykorzystującym tylko cieplne oddziaływanie wiązki laserowej do niezbyt szybkiego odparowania materiału, który w wyniku zjawisk fizycznych (metody PVD) lub chemicznych (metody CVD) jest osadzany sam lub w połączeniu z gazem reaktywnym na określonym podłożu [24]. Tą metodą można odparowywać tytan, który po przereagowaniu z azotem i utworzeniu azotku tytanu jest osadzany na materiale.

Reasumując, wiązki laserowej można użyć do tworzenia powłoki azotku tytanu na pierścieniu tłokowym, stosując technologię wtopieniowego stopowania gazowego oraz jako czynnika grzewczego do odparowania tytanu w technologiach CVD i PVD.

\section{Technologie implantacyjne}

Technologie implantacyjne polegają na zmianie struktury warstwy wierzchniej przez oddziaływanie na nią jonów, które są w niej osadzane, powodują jej trawienie lub rozpylanie. Cechą charakterystyczną struktur zaimplantowanych jest przesycenie materiału implantowanego. Na skutek tarcia dochodzi do tzw. quasi-implantacji, czyli migracji jonów zaimplantowanych. W ten sposób, z początkowej grubości ok. $1 \mu \mathrm{m}$, otrzymuje się zaimplantowanie na głębokość wielokrotnie większą; nawet do $30 \mu \mathrm{m}$ [32]. Poza licznymi zaletami implantacja jonów ma również wady związane z bombardowaniem jonami obszaru o małej szerokości, małej głębokości implantacji (poniżej $1 \mu \mathrm{m}$ ) oraz braku możliwości implantowania elementów o skomplikowanych kształtach i głębokich otworów.

Przydatne w procesach tworzenia powłoki azotku tytanu mogą być technologie mieszania jonowego międzyfazowego gazem szlachetnym oraz mieszania jonowego dynamicznego równocześnie obojętnych lub reaktywnych jonów i atomów naparowanych lub rozpylanych innymi metodami.

Mieszanie jonowe międzyfazowe jest procesem polegającym na poprawie połączenia powłoki z podłożem przez wymieszanie jonowe granicy faz w wyniku bombardowania jonami gazu szlachetnego. W ten sposób poprawia się połączenie nakładanych dowolną metodą powłok azotku tytanu na stale, żeliwa i inne materiały. Wzrost temperatury powoduje wyraźną aktywację procesu - brak wpływu przy temperaturze elementu $100^{\circ} \mathrm{C}$ na zmiany strukturalne i połączenia dyfuzyjnego z podłożem w $500^{\circ} \mathrm{C}$ [16].

Mieszanie jonowe dynamiczne to proces, w którym tytan odparowuje pod działaniem wiązki elektronów i osiada na materiale implantowanym, gdzie jednocześnie jest bombardowany jonami azotu [10]. Podczas tego procesu tworzy się warstwa przejściowa o grubości $40 \mathrm{~nm}$, w której są zaimplantowane jony azotu. Połączenie tą metodą powłoki i materiału jest $10 \div 45$-krotnie wytrzymalsze od zwykłego połączenia adhezyjnego [2], zaś grubość nanoszonej powłoki nie jest ograniczona względami fizycznymi.

Wśród technologii implantacyjnych, jako możliwa do osadzania powłoki azotku tytanu na pierścieniu tłokowym jest zatem technologia mieszania jonowego dynamicznego oraz jako wspomagająca (zwiększająca wytrzymałość połączenia powłoki z podłożem) technologia mieszania jonowego międzyfazowego.

\section{Technologie jarzeniowe}

Do obróbek jarzeniowych należą technologie azotowania, węgloazotowania, siarkowania, nawęglania, borowania i krzemowania, realizowane w obecności wyładowania jarzeniowego, oraz metody PACVD (Plasma Assisted Chemical Vapour Deposition), czyli osadzania z udziałem reakcji chemicznej w warunkach aktywacji elektrycznej środowiska gazowego, mające na celu wytwarzanie twardych warstw powierzchniowych, m.in. węglików, azotków, borków, tlenków metali przejściowych [14].

Osadzanie powłok z azotku tytanu w warunkach wyładowania jarzeniowego jest możliwe dzięki zjawisku chemisorpcji, które występuje w podwyższonej temperaturze. Wzrost szybkości tego procesu następuje dzięki rozpylaniu jonowemu powodującemu oczyszczenie powierzchni oraz obecności aktywnych cząstek pierwiastka tworzącego warstwę powierzchniową, czyli atomów i jonów tytanu oraz atomów i jonów azotu [27]. 


\section{Technologie osadzania próżniowego CVD}

Klasyczne niewspomagane technologie CVD (Chemical Vapour Deposition), czyli chemicznego osadzania z fazy gazowej, przebiegają w temperaturze $1000 \div 1500 \mathrm{~K}$ [27]. W tym zakresie temperatury uzyskiwana jest powłoka azotku tytanu TiN, przy czym materiał osadzany jest umieszczony $w$ gazie zawierającym halogenek tytanu $\mathrm{TiCl}_{4}$, wodór $\mathrm{H}_{2} \mathrm{i}$ azot $\mathrm{N}_{2}$ [26]. Tak wysoka temperatura powoduje niepożądane zmiany strukturalne w elementach, ale zapewnia dobrą przyczepność powłoki do podłoża [15]. Wśród metod wspomaganych CVD, za pomocą których można osadzić powłokę azotku tytanu, należy wymienić metodę PACVD (Plasma Assisted CVD), w której proces prowadzony jest $w$ temperaturze $770 \div 820 \mathrm{~K}$. Stosowany jest taki sam skład mieszaniny gazowej jak w CVD i obniżone ciśnienie do $3 \div 13 \mathrm{hPa}$ oraz inne technologie opisane w [1, 31].

Ciekawe możliwości oferują metody osadzania powłok, w tym azotku tytanu, z aktywacją elektryczną środowiska gazowego technologią wyładowania jarzeniowego $z$ zastosowaniem atmosfer gazowych zawierających związki organiczne, np.: czteropropyloksytytan - Ti $\left(\mathrm{OC}_{3} \mathrm{H}_{7}\right)_{4}$ lub Ti $\left[\mathrm{N}\left(\mathrm{CH}_{2} \mathrm{CH}_{3}\right)_{2}\right]_{4}$, lub Ti $\left[\mathrm{N}\left(\mathrm{CH}_{3}\right)_{2}\right]_{4}$. Są to tzw. metody MOCVD (Metall - Organic CVD). Powłoki te mają dobrą przyczepność do podłoża. W procesie rozpylania katodowego następuje wstępne azotowanie podłoża, a azot znajdujący się w materiale w wyniku tego procesu bierze aktywny udział w tworzeniu powłok TiN, TiC, TiCN lub Ti(O,C,N). Uzyskane powłoki mają dużą twardość $1500 \div 2200 \mu \mathrm{HV}$ dla TiN i Ti(O,C,N) oraz 3000 $4000 \mu \mathrm{HV}$ dla TiC. Grubość uzyskanej powłoki sięga $15 \mu \mathrm{m}$ i cechuje się bardzo dobrą odpornością na zużycie w styku trącym.

Powłokę azotku tytanu można uzyskać, stosując metody PACVD (Plasma Assisted CVD) oraz MOCVD (Metall - Organic CVD), a otrzymane powłoki charakteryzują się bardzo dobrymi właściwościami trybologicznymi i dobrą przyczepnością do podłoża. Wadą tych technologii jest konieczność utylizacji szkodliwych gazów pozostałych po procesie osadzania. Tej wady są pozbawione metody PVD.

\section{Technologie PVD}

Technologie PVD (Physical Vapour Deposition) polegają na wykorzystaniu różnych zjawisk fizycznych przebiegających przy ciśnieniu obniżonym do $10 \div 10^{-5} \mathrm{~Pa}$ (różnym w różnych metodach PVD) $[12,23]$.

Metody PVD charakteryzują się możliwością stosowania czystych metali i gazów jako materiałów wyjściowych zamiast ich szkodliwych związków występujących w metodach CVD [18]. Uzyskanie powłoki jest często związane z dużymi kosztami osadzania oraz koniecznością zapewnienia dużej czystości powierzchni elementów przed procesem. Rekompensowane jest jednak wysoką wydajnością przy stosowaniu specjalistycznych napylarek, dobrymi i bardzo dobrymi właściwościami fizykomechanicznymi powłok oraz ekologicznością procesu.

Prawie zawsze we współczesnych metodach PVD osadzanie powłoki jest realizowane ze strumienia zjonizowanej plazmy kierowanej elektrycznie na stosunkowo zimne podłoże. Są to metody wspomagane plazmą; PAPVD (Plasma Assisted PVD). Energia jonu jest rzędu energii wiązania atomów na powierzchni powłoki, nie przekracza jednak energii rozpylania i jest równa od kilku do kilkudziesięciu eV. Dzięki temu następuje desorpcja zanieczyszczeń, wzrost ilości defektów powierzchniowych, zwiększenie ruchliwości powierzchniowej atomów oraz wzrost aktywności chemicznej powierzchni, co w efekcie powoduje dobrą adhezję powłoki do podłoża [37].

Opracowano wiele metod PVD, za pomocą których można osadzać powłoki azotku tytanu (TiN). Do osadzenia jej na pierścieniu tłokowym najczęściej stosuje się niżej opisane. $Z$ uwagi na przebieg procesu osadzania powłok TiN przy obniżonym ciśnieniu, metody te należy zaliczyć do metod PAPVD [7, 28].

Odparowanie miejscowe łukiem elektrycznym (Arc lub $A E$ ). Polega ono na wywołaniu na powierzchni katody silnoprądowego $(25 \div 100 \mathrm{~A}$, gęstość prądu $10^{6} \div 10^{8} \mathrm{~A} / \mathrm{cm}^{2}$ ) niskociśnieniowego wyładowania łukowego o mocy kilku kilowatów pomiędzy grubą, chłodzoną wodą tarczą a pierścieniową anodą, również chłodzoną wodą [4]. Wyładowanie jest zlokalizowane w plamkach katodowych będących źródłem wysoko

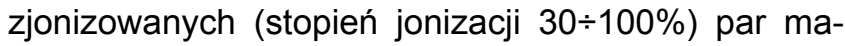
teriału (odparowanie miejscowe) [12]. Prędkość, kierunek i odległość przemieszczania się są sterowane za pomocą ekranów elektrostatycznych. Metoda ta cechuje się występowaniem jonów wielokrotnych, wysoką energią kinetyczną jonów $(10 \div 1000 \mathrm{eV})$ oraz możliwością czyszczenia jonowego podłoża [7]. Podstawowym zjawiskiem $\mathrm{w}$ wyładowaniu łukowym w próżni jest pojawianie się, dryf i zanikanie wspomnianych wyżej plamek katodowych. Prędkość nakładania powłok jest równa ok. $3,5 \mu \mathrm{m} / \mathrm{h}$. Istnieje możliwość umieszczenia kilku (do 12) katod z różnych materiałów w jednym urządzeniu i osadzania powłok kompozytowych i wielowarstwowych odparowywanych w atmosferze mieszaniny gazów reaktywnych [14]. Przykładem może być nakładanie powłok Ti(Al,N) [3]. W plazmie metalicznej występują krople odparowanego materiału, które biorą udział w tworzeniu powłoki, co jest wadą, ale ich udział może być regulowany odpowiednią konstrukcją katody, ruchem plamek i filtrowaniem sadzy.

Bezpośrednie reaktywne rozpylanie magnetronowe (MS). W metodzie tej materiał zwany tarczą jest rozpylany przez jony gazu wytworzone w obszarze między plazmą a wsadem. Metoda umożliwia rozpylanie tarcz nie tylko z materiałów przewodzących, ale też z dielektryków [22]. Obecność silnego pola magnetycznego 
w pobliżu katody powoduje zwiększenie stopnia jonizacji w przestrzeni przykatodowej, a tym samym znaczny wzrost intensywności rozpylania materiału katody w porównaniu z klasycznym rozpylaniem katodowym. Rozpylone atomy przechodzą przez obszar plazmy, ulegając jonizacji $\mathrm{i}$ - reagując $\mathrm{z}$ jonami oraz atomami gazu reaktywnego - osadzaja się w postaci związku chemicznego na wsadzie [7]. Proces odbywa się w obecności wyładowania jarzeniowego w skrzyżowanych polach elektrycznych i magnetycznych, czyli w magnetronie [7, 34]. Zwrócono uwagę na nierównomierność grubości warstwy osadzanej powłoki w zależności od zastosowanego kształtu magnetronu oraz ogólnie na znaczny rozrzut grubości powłoki na powierzchni o skomplikowanych kształtach [29, 35].

Odparowanie impulsowo-plazmowe. Polega na odparowaniu ze stanu stałego umieszczonej centralnie w generatorze plazmy elektrody wykonanej z materiału powłokowego w wyniku silnoprądowego (100 kA) impulsowego rozładowania baterii kondensatorów o napięciu $1 \div 10 \mathrm{kV}[14,17]$. Czas ogrzewania podłoża plazmą (stanowiącą wysokodyspersyjny aerozol np.: azotku tytanu) o temperaturze $2000 \mathrm{~K}$ jest krótszy od $100 \mu \mathrm{s}$ i powoduje przyrost temperatury z prędkością $10^{7} \mathrm{~K} / \mathrm{s}$, a prędkość chłodzenia w WW elementu, wywołana odpływem ciepła do pozostałej masy elementu, jest równa $10^{5} \mathrm{~K} / \mathrm{s}$. Czas pomiędzy odparowaniami wynosi $5 \mathrm{~s}$. Dzięki temu, że czas ogrzewania podłoża jest tak krótki, a zarodki krytyczne zawarte w aerozolu tak małe (rzędu $10^{-9} \mathrm{~m}$ ), że wykazują ruch po podłożu, temperatura podłoża nie przekracza $500 \mathrm{~K}$. Przy tym adhezja powłoki do podłoża jest odpowiednio duża [28]. Sterowanie procesem odbywa się za pomocą zewnętrznego lub własnego pola magnetycznego.

\section{Wybór metody pokrywania pierścienia tłokowego powłoką z azotku tytanu}

Po przeprowadzeniu analizy metod osadzania powłok na elementach maszyn stwierdzono, że najkorzystniejszym procesem tworzenia powłoki azotku tytanu na powierzchni roboczej pierścienia tłokowego jest technologia PAPVD, czyli fizycznego osadzania z fazy gazowej powłok wspomagana plazmą. Przy czym równorzędne efekty daje metoda łukowa odparowania substratu (tytanu) i metoda magnetronowa. Ponadto duże nadzieje wiąże się z zastosowaniem wiązki laserowej w technologii wtopieniowego stopowania gazowego z uwagi na możliwość otrzymania powłoki o grubości nawet do $100 \mu \mathrm{m}$, jednak wymagającej dalszej obróbki wykańczającej powierzchni.

Ostatecznie ze względu na nierównomierną grubość powłok azotku tytanu otrzymywanych metodą magnetronową podjęto decyzję o jej wykonaniu metodą łukowo - próżniową.

\section{Wykonanie powłoki z azotku tytanu metodą łukowo - próżniową na pierścieniu tłokowym}

\section{Przygotowanie powierzchni pierścienia tłokowego}

Aby uzyskać powłokę o żądanych właściwościach, należy dobrać składniki ją tworzące, parametry technologiczne procesu oraz przygotować podłoże. Przed osadzeniem powłoki należy przeprowadzić obróbkę cieplną oraz wykańczającą powierzchni elementu poddanego tej technologii. Należy zapewnić nierówności powierzchni $R a<0,8 \mu \mathrm{m}$ [5]. Oczyszczanie powierzchni elementu składa się z dwóch etapów: oczyszczania wstępnego (mechaniczne, chemiczne, fizyczne i fizykochemiczne) oraz oczyszczania ostatecznego, które jest realizowane $\mathrm{w}$ procesie trawienia jonowego $[6,7,9]$. $W$ czasie tego procesu następuje wzrost temperatury elementu, który jest zależny od kształtu, masy i jego wymiarów. Adhezja powłoki rośnie wraz z jej grubością do osiągnięcia grubości ok. $1,5 \div 2,0 \mu \mathrm{m}$ [7]. Po przekroczeniu tej granicy siła adhezji nie ulega zmianie, jednakże rosną naprężenia na granicy powłoka - podłoże. W związku z tym grubość powłok osadzanych metodami PAPVD zawiera się zwykle w granicach $1 \div 4 \mu \mathrm{m}$ [7]. Niezmiernie istotną rolę w przyczepności powłoki do podłoża odgrywa warstwa przejściowa. W przypadku powłok z TiN można uzyskać warstwy przejściowe o budowie dyfuzyjnej lub pseudodyfuzyjnej. Warstwy dyfuzyjne wymagają jednak wysokiej temperatury osadzania i z tego względu ich utworzenie nie jest możliwe. Warstwa pseudodyfuzyjna może powstać podczas procesu trawienia jonowego powierzchni. Wspomniany proces rozpylania katodowego, a szczególnie platerowanie jonowe prowadzi do rozpylenia materiału powierzchni podłoża i implantacji cząsteczek materiału powłoki. Jest to podstawową przyczyną lepszej przyczepności powłok osadzonych $w$ procesie rozpylania $i$ platerowania jonowego niż w procesie naparowywania powłoki [7].

\section{Charakterystyka powłoki TiN}

Powłoki osadzane metodami PVD charakteryzują się znaczną zmiennością składu chemicznego, co wywołuje zmiany rodzaju wiązań i struktury metalograficznej [8]. Struktura warstwy osadzanej metodami PAPVD jest wyraźnie wielofazowa. Skład fazowy warstw Ti-N obejmuje: $\delta$-TiN, $\varepsilon-\mathrm{Ti}_{2} \mathrm{~N}$ oraz $\alpha$-Ti. Twardość powłoki jest ściśle związana $z$ jej składem chemicznym i fazowym. W powłoce napotyka się cząstki powstałe z substratów, których trwałość określa energia wiązania. W przypadku otrzymywania powłok z azotku tytanu tworzą się $\mathrm{Ti}_{2} \mathrm{~N}, \mathrm{Ti}_{2} \mathrm{~N}+\mathrm{TiN}$ oraz czysty TiN. Występujące w powłoce wiązania mają charakter metaliczny $(M)$, 
kowalencyjny (K) lub jonowy (J). Brak w niej wiązań czystej postaci [20]. Przeważają wiązania mieszane, tworzące złożone kombinacje: metal-metal, metalniemetal, niemetal-niemetal. Poszczególne rodzaje wiązań wykazują odmienne właściwości. Najbardziej zbliżone do uniwersalnych mają materiały o wiązaniu metalicznym (M) [8]. Z punktu widzenia trybologicznego właściwości azotku tytanu są pośrednie pomiędzy trzema rodzajami wiązań, zajmując środkowe położenie w klasyfikacji twardych materiałów zgodnie $z$ charakterem ich wiązań $[8,20]$. TiN charakteryzuje się małym powinowactwem do materiałów współpracujących, a ze względu na małą kruchość zachowuje dobre właściwości przeciwzużyciowe w przypadku zmiennych obciążeń [33]. Cecha ta jest szczególnie ważna dla pierścienia tłokowego poddawanego ustawicznie zmiennym obciążeniom mechanicznym i cieplnym. Powłoki z azotku tytanu wykazuja dużą odporność na utlenianie $w$ temperaturze do $450 \div 500^{\circ} \mathrm{C}$. Przekroczenie tej temperatury powoduje powolne utlenianie powłok. Temperatura pierścienia tłokowego nie przekracza we współczesnych silnikach $350^{\circ} \mathrm{C}$, w związku z tym nie zachodzi obawa o utlenienie naniesionej powłoki.

\section{Literatura}

[1] Arai T., Fujita H.: Plasma-assisted CVD of TiN and TiC on steel, Proceedings of 6th International Conference on lon and Assisted Techniques, Bringhton U.K., May 1987, s. 196-200.

[2] Armini A.: Formation of new surface alloys by ion implantation technology, Industrial Heating, January 1986, s. 17-19.

[3] Barbaszewski T., Dąbrowski M., Gawlik J.: Technologia i właściwości twardych pokryć TiAIN na podłożu ze stali szybkotnącej, Materiały konferencyjne INSYCONT'90, Kraków 1990, s. 147-152.

[4] Betiuk M.: PVD-Arc - sterowanie i struktura warstw, Materiały Ogólnopolskiej Konferencji „Nowoczesne technologie w inżynierii powierzchni”, Łódź-Spała, 22-23 września 1994.

[5] Bromark M., Larsson M., Hedenqvist P., Olsson M., Hogmark S.: Influence of substrate surface topography on the critical normal force in scratch adhesion testing of TiN - coated steels, Surface of Coating Technology, 52(2), 195-203 (1992).

[6] Bujak J., Miernik K., Smolik J., Walkowicz J.: Przygotowanie powierzchni detali do osadzania warstw metodami PAPVD $\mathrm{z}$ zastosowaniem trawienia jonowego, Wybrane zagadnienia inżynierii powierzchni, Politechnika Rzeszowska 1992, s. 32.

[7] Bujak J., Miernik K, Smolik J., Walkowicz J.: Otrzymywanie warstw TiN i TiAIN metodami: magnetronową i łukowo-próżniową, Problemy Eksploatacji, nr 3, 1992, s. 157-161.

[8] Bujak J., Miernik K., Smolik J., Walkowicz J.: Właściwości materiałów stosowanych na twarde powłoki, Materiały VII Krajowego Sympozjum Eksploatacji Urządzeń Technicznych, Radom-Kozubnik 1993, Tribologia, nr 4/5, 1993, s. 77-83.

[9] Bujak J., Miernik K., Rogowska R., Smolik J., Walkowicz J.: Przygotowanie powierzchni narzędzi dla nanoszenia powłok przeciwzużyciowych metodami PVD, Przegląd Mechaniczny, nr 44, 1994, s. 12-15.

[10] Burakowski T.: Implantacja jonów i możliwości jej zastosowania do modyfikacji warstwy wierzchniej metali, Tribologia, nr 5, 1089, s. 4-12.

[11] Burakowski T.: Wiązka elektronowa i możliwości jej wykorzystania do poprawy właściwości powierzchni, nr 8-9, Mechanik, 1992, s. 281-284.

[12] Burakowski T., Miernik K., Walkowicz J.: Zastosowanie fizykochemicznych technologii wspomaganych plazmą do wytwarzania cienkich powłok odpornych na zużycie, Metaloznawstwo, Obróbka cieplna, Inżynieria Powierzchni, nr 130132, 1995

[13] Burakowski T., Roliński E., Wierzchoń T.: Inżynieria powierzchni metali, Wydawnictwa Politechniki Warszawskiej, Warszawa 1992.

[14] Burakowski T., Wierzchoń T.: Inżynieria powierzchni metali, Wydawnictwa Naukowo-Techniczne, Warszawa, 1995

[15] Celiński Z., Miernik K.: Plazmowo-chemiczne metody wytwarzania warstw odpornych na zużycie, Tribologia, nr 6, 1991, s. 6-11.

[16] Eredmir A., Cheng C.C.: Nucleation and growth mechanisms in ion-plated TiN films on steel substrates, Surface and Coating Technology, nr 41, 1990, s. 285-293:

[17] Gokieli B.: Fizykochemiczne aspekty powstawania fazy skondensowanej w plazmie impulsowej obserwowanej metodami spektralnymi, Rozprawa doktorska PW, Warszawa 1980,

[18] Hebda-Dutkiewicz E.: Twarde warstwy nanoszone metodami PVD, Międzyresortowe Centrum Eksploatacji Majątku Trwałego, Radom 1990.

[19] Hegge H.J., de Hossen J.Th.M.: The influence of convection on the homogenity of laser applied coatings, Surface Engeenirig Praxice - Processes, Fundamentals and Application in Corrosion and Wear, Wyd. Ellis Horwood, New York-Toronto-Sydney-Tokyo-Singapoore 1989, s. 160-167.

[20] Hollek H.: Basic principles of specific applications of ceramic materials as protective layers, Surface and Coating Technology, 43/44, 1990, s. 245-258.

[21] Kaminsky M.: Atomic and ionic phenomena on metal surface, Springer-Verlag, Berlin-New York, 1965.

[22] Leja E., Horodyski T., Budzyńska K.: Magnetronowa technika wytwarzania cienkich warstw, Elektronika, nr 9, 1982, s. 5-7.

[23] Markowski J., Marków Z., Prajzner A.: Urządzenie do nanoszenia warstw azotku tytanu metodą aktywowanego reaktywnego naparowywania (BARE), Elektronika, nr 2, 1988, s. 28-30.

[24] Matsunawa A., Katayama S., Miyazawa H., Hiramoto S.: Oka K., Ohmine M.: Basic study on laser vapour deposition of ceramics, Surface and Coating Technology, 43/44, 1990, s. 176-184.

[25] Michalski J.: Metody PVD stosowane do nanoszenia warstw materiałów twardych i trudnotopliwych na narzędzia skrawające, Metaloznawstwo, Obróbka Cieplna, nr 79, 1986, s. 18-23.

[26] Michalski J.: Warunki tworzenia się warstw powierzchniowych w procesach chemicznego osadzania $z$ fazy gazowej $w$ atmosferach $\mathrm{TiCl}_{4}+\mathrm{H}_{2} \mathrm{i} \mathrm{TiCl}_{4}+\mathrm{H}_{2}+\mathrm{N}_{2}$, Rozprawa doktorska, Politechnika Warszawska, 1989.

[27] Michalski J., Wierzchoń T.: CVD of TiN layers in various glow discharge regions, Journal of Materials Science Letters, $\mathrm{nr} 10$, 1991, s. 506-510.

[28] Michalski A., Zdunek K., Sokołowska A., Olszyna A.: Impulsowo-plazmowa metoda nanoszenia warstw TiN na narzędzia w temperaturze niższej niż $500 \mathrm{~K}$, Przegląd Mechaniczny, nr 15, 1991, s. 7-10.

[29] Miernik K., Walkowicz J., Kułakowska-Pawlak B., Żyrnicki W.: Deposition of wear-resistant TiN layers in linear magnetron sputtering system, Zagadnienia Eksploatacji Maszyn, nr 2 (114) 1998, Wydawnictwo Naukowe PWN, Warszawa 1998, s. 287-291.

[30] Pobol I.J.: Tendencje światowe w zastosowaniach wysokoenergetycznych wiązek elektronowych do obróbki metali, Elektronika, nr 8-9, 1993, XXXIV, s. 41-47. 
[31] Rie K.T., Lampe T., Eisenberg S.: Abscheinung von Titaninnitridschichten mittels Plasma - CVD, Härterei Technische Mitteilungen, 42, 1987, nr 3, s. 153-161.

[32] Rosiński W.: Zastosowanie wiązki jonowej do modyfikacji właściwości ciała stałego, Referaty I Konferencji Naukowej „Technologia elektronowa”, Wrocław-Kudowa, wrzesień 1982, s. $175-185$.

[33] Smolik J.: Mechanizmy zużywania się powłok przeciwzużyciowych na narzędziach skrawających jako istotny aspekt doboru powłok w zależności od warunków ich późniejszego zastosowania, Tribologia 4-5/93 (130-131), Radom 1993, s. $271-276$, s. $363-368$.

[34] Staśkiewicz J., Czyżniewski A.: Warstwy azotku tytanu otrzymane zmodyfikowaną metodą reaktywnego stałoprądowego rozpylania magnetronowego, Materiały Konferencji Naukowej „Techniki wytwarzania warstw powierzchniowych metali”, Rzeszów, czerwiec 1988, s. 99-103.
[35] Tasak E., Jankowski H., Drewnowska M., Gola W.: Wykorzystanie metody PVD w technologii produkcji łożysk ślizgowych, Perspektywy rozwojowe konstrukcji, technologii i eksploatacji pojazdów samochodowych i silników spalinowych, Konferencja KONMOT’96, Kraków 1996, s. 285-292.

[36] Wierzchoń T., Sobiecki J.R., Kurzydłowski K.: Properties of surface layers produced from metaoorganic compounds, Thin films, Ed. G. Hecht, F. Richter, J. Hahn, DGM, Verlag, 1994, s. $195-198$.

[37] Yuansheng J., Huadong W., Nicoll A.R., Barbezat G.: The tribological behaviour of various plasma - sprayed coatings against cast iron, Surface and Coating Technology, 52(2), 1992, s. 169-178.

\section{Wydarzenia}

\section{Sympozjum Katedr i Zakładów Spawalnictwa Nowoczesne zastosowania technologii spawalniczych Byczyna, 19 - 20 czerwca 2012}

Po kilkunastoletniej przerwie Katedra Spawalnictwa Politechniki Śląskiej wraca do tradycji organizowania spotkań środowisk związanych z kształceniem na poziomie akademickim specjalistów z zakresu spawalnictwa - Seminariów Katedr i Zakładów Spawalnictwa. Intencją organizatorów jest, aby spotkania te stały się ponownie miejscem integracji, wymiany doświadczeń i prezentacji dorobku naukowego i dydaktycznego studenckich kół naukowych oraz pracowników naukowo-dydaktycznych jednostek związanych z kształceniem inżynierów spawalników.

Inicjatywa zorganizowania Seminarium Katedr i Zakładów Spawalnictwa w 2012 r. wyszła od przedstawicieli Studenckiego Koła Naukowego "Strefa Wpływu Ciepła" SWC działającego przy Katedrze Spawalnictwa Politechniki Śląskiej. W organizację seminarium włączyła się również Katedra Spawalnictwa i Polskie Towarzystwo Spawalnicze. W tegorocznym sympozjum, które odbyło się w Byczynie w dniach 19 - 20 czerwca wzięło udział 59 uczestników w tym 22 studentów. Autorami 24 referatów byli pracownicy naukowi i studenci Politechnik: Śląskiej, Częstochowskiej, Rzeszowskiej, Świętokrzyskiej, Warszawskiej, Wrocławskiej, Gdańskiej, AGH oraz Instytutu Spawalnictwa. Spotkanie zaszczycili swoją obecnością m.in. Prof. Edmund Tasak, Prof. Jacek Senkara, Prof. Antoni Orłowicz, Prof. Jerzy Łabanowski, Prof. Janusz Adamiec, Prof. Jacek Słania oraz Prof. Andrzej Gruszczyk.

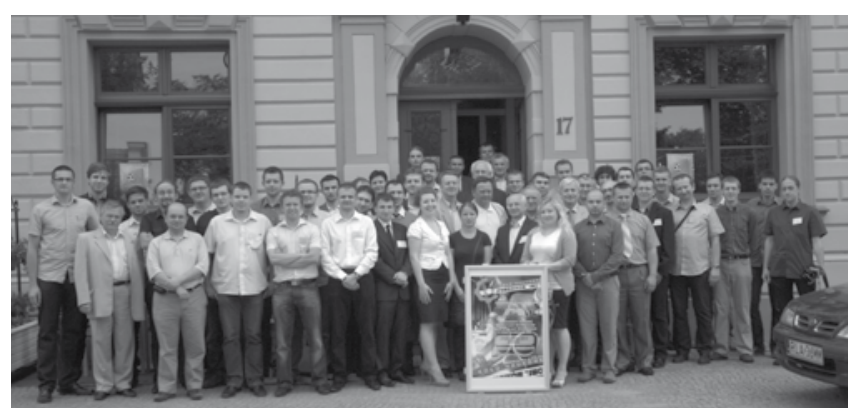

Uczestnicy Sympozjum Katedr i Zakładów Spawalnitwa, Byczyna, 19 - 20 czerwca 2012

Komitet organizacyjny: dr hab. inż. Andrzej Gruszczyk, prof. PŚl, dr hab. inż. Janusz Adamiec, prof. PŚl, dr inż. Artur Czupryński, dr inż. Jacek Górka, dr inż. Tomasz Kik, mgr inż. Jarosław Parylak, mgr inż. Marek Burda, inż. Łukasz Bigus, inż. Dariusz Kłosek, inż. Bartłomiej Kotkowski, Teresa Dąbrowska-Mikuła

Komitet naukowy: dr hab. inż. Janusz Adamiec, prof. PŚl, dr hab. inż. Andrzej Ambroziak, prof. PWr, dr hab. inż. Andrzej Gruszczyk, prof. PŚı, dr hab. inż. Jerzy Łabanowski, prof. PG, dr hab. inż. Zbigniew Mirski, prof. PWr, prof. dr hab. inż. Jerzy Nowacki, prof. $\mathrm{dr}$ hab. inż. Antoni W. Orłowicz, dr inż. Jan Plewniak, prof. dr hab. inż. Jacek Senkara, dr hab. inż. Jacek Słania, prof. nzw. w IS, prof. dr hab. inż. Edmund Tasak, dr hab. inż. Eugeniusz Turyk, prof. nzw. w IS

Mgr inż. Marek Burda 